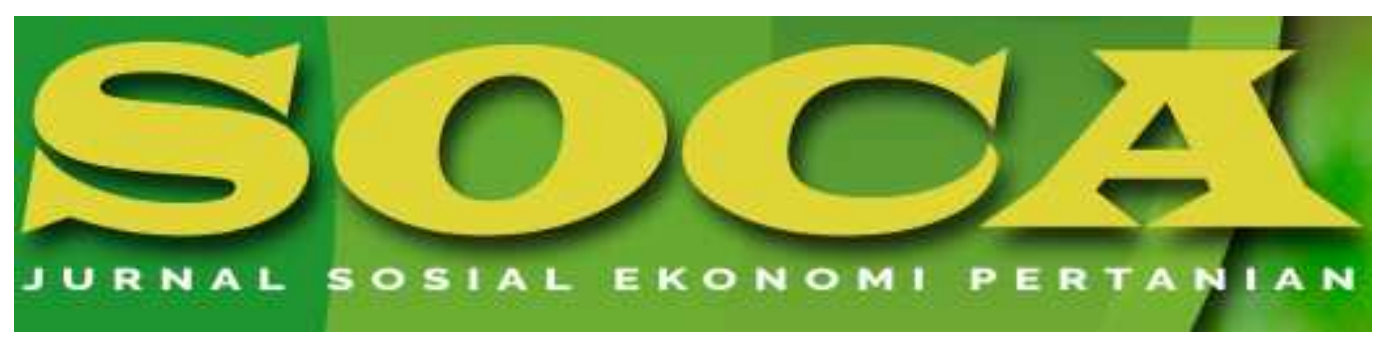

https://ojs.unud.ac.id/index.php/soca

\title{
ANALISIS PENDAPATAN USAHATANI MONOKULTUR KENTANG DAN TUMPANGSARI KENTANG-CARICA DESA SEMBUNGAN KECAMATAN KEJAJAR KABUPATEN WONOSOBO
}

\author{
Diar Rizqika Herliani, Djoko Sumarjono dan Bambang Mulyatno Setiawan \\ Program Studi S1 Agribisnis, Fakultas Peternakan dan Pertanian, \\ Universitas Diponegoro, Tembalang, Semarang, Jawa Tengah \\ Email: diarherliani@gmail.com, Telepon/HP: 0895349965367
}

\begin{tabular}{l} 
Kata Kunci: \\
Carica, \\
Kentang, \\
monokultur, \\
tumpangsari, \\
pendapatan \\
bersih, \\
profitabilitas, \\
R/C ratio \\
\hline
\end{tabular}

Kata Kunci:

Carica,

Kentang, monokultur, tumpangsari, pendapatan bersih, $\mathrm{R} / \mathrm{C}$ ratio

\begin{abstract}
Abstrak
Pola tanam petani di Desa Sembungan secara monokultur dan tumpangsari. Penelitian ini mengkaji tentang lebih menguntungkan dan dapat mengevaluasi pola tanam yang menggunakan tumpangsari dan monokultur. Petani di Desa Sembungan belum memperhatikan faktor biaya operasional, pendapatan bersih, dan kelayakan keberlanjutan yang diukur dengan $\mathrm{R} / \mathrm{C}$ ratio. Tujuan penelitian ini untuk menganalisis pendapatan bersih, profitabilitas dan $\mathrm{R} / \mathrm{C}$ ratio pada usahatani dengan pola tanam yang berbeda yaitu pola tanam monokultur kentang dan pola tanam tumpangsari kentang-carica. Metode penelitian ini dilakukan dengan metode survei. Penentuan lokasi menggunakan metode purposive. Penetuan jumlah responden dilakukan dengan metode nonprobability sampling yaitu sampling kuota. Sampel yang ditentukan sebanyak 30 petani kentang dan 30 petani kentang-carica. Penentuan responden dengan cara snowball sampling. Analisis menggunakan twosample assuming equal variences dengan microsoft excel. Hasil penelitian menunjukan pendapatan bersih usahatani tumpangsari kentang carica lebih besar secara nyata dari pendapatan bersih monokultur kentang. Pendapatan bersih usahatani tumpangsari kentangcarica yaitu Rp 17.386.588,2 / ha/MT dan pendapatan bersih monokultur kentang yaitu Rp 7.537.404,3 ha/MT. Profitabilitas dari usahatani dengan pola tanam tumpangsari kentang carica lebih besar secara nyata dari usahatani dengan pola tanam monokultur kentang. Profitabilitas usaha tani monokultur kentang yaitu $44,07 \%$ dan profitabilitas pola tanam tumpangsari
\end{abstract}


kentang-carica yaitu 60,39\%. $\mathrm{R} / \mathrm{C}$ ratio dari usahatani dengan pola tanamtumpangsari kentang carica lebih besar secara nyata dari usahatani dengan pola tanam monokultur kentang. $\mathrm{R} / \mathrm{C}$ ratio usaha tani dengan pola tanam tumpangsari yaitu 1,60 dan usaha tani dengan pola tanam monokultur kentang yaitu 1,44 .

THE INCOME ANALYSIS OF MONOCULTURE POTATO FARMING AND INTERCROPPING OF CARICA-POTATOES IN SEMBUNGAN VILALLAGE, KEJAJAR SUB-DISTRICT, WONOSOBO REGENCY

\begin{tabular}{l}
\hline Keywords: \\
Carica, \\
intercropping, \\
monoculture, net \\
income, \\
pendapatan, \\
potato, \\
profitability, \\
$R / C$ ratio \\
\hline
\end{tabular}

\begin{abstract}
Abstrak
Cropping petterns of farmers in Sembungan Village are monoculture and intercropping. This study examines more profitable and can evaluate cropping patterns using intercropping and monoculture. Farmers in Sembungan Village have not paid attention to operational costs, net income and sustainability feasibility as measured by the $R / C$ ratio. This reasearch aims to analyze net income, profitability and $R / C$ ratio of the planting system potato monoculture and the planting system potato-carica intercropping. The reasearch method used survey method location was decided by purposive method. The number of respondents decided by nonprobability sampling that is sampling quota. The samples determined by 30 potato farmers and 30 potato-carica farmers. Respondent decided by snowball sampling. The analyze used two-sample assuming equal variences used microsoft excel. The results of reasearch that the net income of potato-carica intercropping significantly higher than the net income of potato monoculture. Net income of potato-carica intercropping is $R p$ 17,386,588.2 and Net income of potato monoculture is $R p 7,537,404$.3. Profitability of potato-carica intercropping significantly higher than the profitability of potato monoculture. Profitability of potato-carica intercropping is $60.39 \%$ and profitability of potato monoculture is $44.07 \%$. $R / C$ ratio of potato-carica intercropping higher than $R / C$ ratio of potato monoculture. $R / C$ ratio of potato-carica intercropping is 1.60 and $R / C$ ratio of potato monoculture is 1.44 .
\end{abstract}

How to Cite (APA 6th Style):

Herliani, D. R., Sumarjono, D., \& Setiawan, B. M. (2019). Analisis Pendapatan Usahatani Monokultur Kentang dan Tumpangsari Kentang-Carica Desa Sembungan Kecamatan Kejajar Kabupaten Wonosobo. SOCA: Jurnal Sosial Ekonomi Pertanian, 13(3), 291-303. https://doi.org/https://doi.org/ 10.24843/SOCA.2019.v13.i03.p01 


\section{PENDAHULUAN}

Pola tanam yang dilakukan petani di Desa Kejajar yaitu tumpangsari dan monokultur. Pola tanam monokultur komoditi kentang sedangkan untuk pola tanam tumpangsari yaitu kentang dan carica. Sistem pertanian ini sudah terjadi secara turun menurun. Penanaman secara monokultur merupakan pola tanam tannpa dicampur dengan budidaya tanaman lain. Pada pola tanam monokulutur kentang di Desa Sembungan memiliki keunggulan pada pengelolaan tanaman lebih mudah karena tanaman yang ditanam seragam dan membutuhkan tenaga kerja yang berlebih sehingga dapat mengurangi biaya pemeliharaan. Kelemahan pada pola tanam monokultur kentang yaitu hama dan serangan penyakit dapat menyebar secara cepat (Pramono et al., 2010). Pola tanam tumpangsari merupakan pola tanam dengan dua atau lebih jenis tanaman yang ditanam pada kurun waktu yang sama dan lahan yang sama. Pola tanam tumpangsari, bagian tengah lahan digunakan untuk menanam kentang dan pohon carica menggunakan samping lahan. Keunggulan pola tanam tumpangsari dapat mengurangi ridiko kerugian yang disebabkan fluktuasi harga pertanian, dapat menekan biaya tenaga kerja, pemeliharaan umum, dan memperbaiki sifat tanah sehingga produktifitas meningkat (Darwis, 2017)

Tanaman carica merupakan tanaman khas daerah Dieng termasuk satu genus dengan pepaya namun mempunyai aroma lebih segar dan harum dan tekstur lebih kenyal dari pepaya (Rahayu dan Pribadi, 2012). Produksi kentang terbesar di Indonesia terdapat di Provinsi Jawa Tengah sebesar 273.513 ton/tahun dan kabupaten Wonosobo dikenal sebagai salah satu penghasil komoditi kentang terbesar di Jawa Tengah (Badan Pusat Statistika, 2015). Petani di Desa Sembungan memasarkan hasil usahatani di pengepul dan di pasar Kecamatan Kejajar.

Pola tanam tumpangsari merupakan pola tanam yang melibatkan dua jenis atau lebih tanaman yang ditanam pada waktu bersamaan. Sistem tanam tumpangsari dapat memberikan keuntungan seperti meningkatkan pendapatan, mengurangi risiko kerugian tanaman, mengurangi hama, serangan penyakit dan gulma. Tanaman carica dapat ditumpangsari dengan kentang. Keanekaragaman mikrobiota tanah dengan pola tanam tumpangsari lebih besar dibandingkan dengan pola tanam monokultur. Biaya yang dikeluarkan untuk pola tanam tumpangsari lebih besar dibandingkan dengan pola tanam monokultur (Pelawi et al., 2016). Pendapatan yang diterima petani dengan pola tumpangsari dengan petani dengan pola tanam monokultur terdpat perbedaan secara signifikan, adanya biaya tambahan pada pola tanam tumpangsari menyebabkan pendapatan lebih besar (Wahyuni et al., 2018). Analisis kelayakan menggunakan $\mathrm{R} / \mathrm{C}$ ratio pada pola tanam tumpangsari ubikayu kacang tanah lebih besar dari monokultur ubikayu (Khasanah, 2016)

Penelitian ini dilatarbelakangi untuk mengetahui lebih menguntungkan dan lebih efisien pola tanam monokultur atau tumpangsari yang dihitung menggunakan pendapatan bersih, profitabilitas dan $\mathrm{R} / \mathrm{C}$ ratio. Hasil penelitian dapat digunakan sebagai evaluasi petani di Desa Sembungan untuk menerapkan pola tanam. Tujuan penelitian ini untuk menganalisis pendapatan bersih, profitabilitas dan $\mathrm{R} / \mathrm{C}$ ratio pada usahatani dengan pola tanam yang berbeda yaitu pola tanam monokultur kentang dan pola tanam tumpangsari kentang-carica. 


\section{METODE PENELITIAN}

Metode penentuan sampel menggunakan nonprobability sampling, penarikan sampel secara tak acak, yaitu sampling kuota. Penentuan sampel pada nonprobability sampling yaitu setiap anggota populasi memiliki kesempatan yang sama (Suryani and Hendryadi, 2015). Jumlah petani yang menanam kentang dan kentang-carica tidak diketahui. Sampel yang ditentukan sebanyak 30 petani kentang dan 30 petani kentang carica. Apabila sampel dibagi dalam kategori maka jumlah anggota sampel setiap kategori minimal 30.Ukuran sampel yang layak dijadikan penelitian antara 30-500 sampel (Sugiyono, 2012). Metode yang digunakan adalah metode penelitian secara kuantitatif dengan teknik survei. Penelitian dengan teknik survei menggunakan bantuan kuesioner yang digunakan untuk wawancara. Data yang diperoleh di tabulasi menggunakan Microsoft Excel dan dianalisis menggunakan SPSS (Statistic Package for Social Science) untuk menganalisis pendapatan bersih, profitabilitas, dan $\mathrm{R} / \mathrm{C}$ ratio. Data meliputi data biaya, penerimaan dan pendapatan.

Penelitian akan dilaksanakan pada bulan Oktober - November 2018 di Desa Sembungan, Kecamatan Kejajar, Kabupaten Wonosobo, Jawa Tengah. Pengumpulan data dilakukan dengan cara wawancara yang dibantu dengan bantuan kuesioner. Data yang diambil dalam penelitian ini adalah data primer dan data sekunder. Data primer didapatkan dari hasil wawancara dengan petani di Desa Sembungan Kecamatan Kejajar Kabupaten Wonosobo. Data Primer yang dikumpulkan meliputi investasi petani, jumlah produksi, biaya yang dikeluarkan per musim tanam, penerimaan yang diterima per musim tanam dan harga yang dijualkan kepada produsen. Data sekunder didapatkan dari Dinas Pertanian Kabupaten Wonosobo meliputi Standar Operasional Prosedur penanaman kentang dan carica, standar produksi kentang dan carica. Badan Pusat Statistika Kabupaten Wonosobo meluputi keadaan kependudukan di Desa Sembungan dan Data Monografi Desa Sembungan di Kantor Desa Sembungan. Data yang diperoleh di tabulasi menggunakan Microsoft Excel dan dianalisis menggunakan SPSS (Statistic Package for Social Science) untuk menganalisis pendapatan bersih, profitabilitas, dan R/C ratio. Data meliputi data biaya, penerimaan dan pendapatan.

Hipotesis 1 : Diduga pendapatan bersih petani menggunakan pola tanam tumpangsari kentang-carica lebih besar dari pendaparan bersih petani menggunakan pola tanam monokultur kentang. Hipotesis 2 : Diduga profitabilitas usahatani menggunakan pola tanam tumpangsari kentang - carica lebih besar dari profitabilitas pola tanam monokultur kentang. Hipotesis 3 : Diduga R/C ratio usahatani menggunakan pola tanam tumpangsari kentang-carica lebih besar dari pola tanam monokultur kentang.

1. Rumus Pendapatan Bersih menurut (Ekowati et al., 2014) adalah sebagai berikut:

a. Pendapatan Bersih (PB)

$$
\mathrm{PB}=\mathrm{PK}-\mathrm{BU}
$$

Keterangan:

PB: Pendapatan Bersih (Rp/ha/MT)

PK: Pendapatan Kotor (Rp/ha/MT)

BU: BAL + UTKK

BAL: Biaya Alat Luar (Rp/ha/MT) 
UTKK: Upah Tenaga Kerja Keluarga (Rp/HOK/MT)

2. Rumus $\mathrm{R} / \mathrm{C}$ ratio menurut (Warisno. and Dahana, 2018) adalah sebagai berikut:

$$
\mathrm{R} / \mathrm{C}=\frac{\mathrm{TR}}{\mathrm{TC}}
$$

Keterangan:

TR : Total Revenue (Rp/ha/MT)

TC : Total Cost (Rp/ha/MT)

$\mathrm{R} / \mathrm{C}$ ratio kurang dari 1 , berarti usaha tani tidak efisien atau tidak menguntungkan. Apabila nilai $\mathrm{R} / \mathrm{C}$ ratio lebih dari 1 , berarti usahatani efisien atau menguntungkan. 3. Rumus Profitabilitas menurut (Budiraharjo et al., 2011)adalah sebagai berikut :

$$
\text { Profitabilitas : } \frac{\text { Pendapatan }}{\text { Biaya Produksi }} \times 100 \%
$$

Data diuji normalitas nya menggunakan uji normalitas, selanjutnya diuji menggunakan uji parametrik independent sample $t$ test.

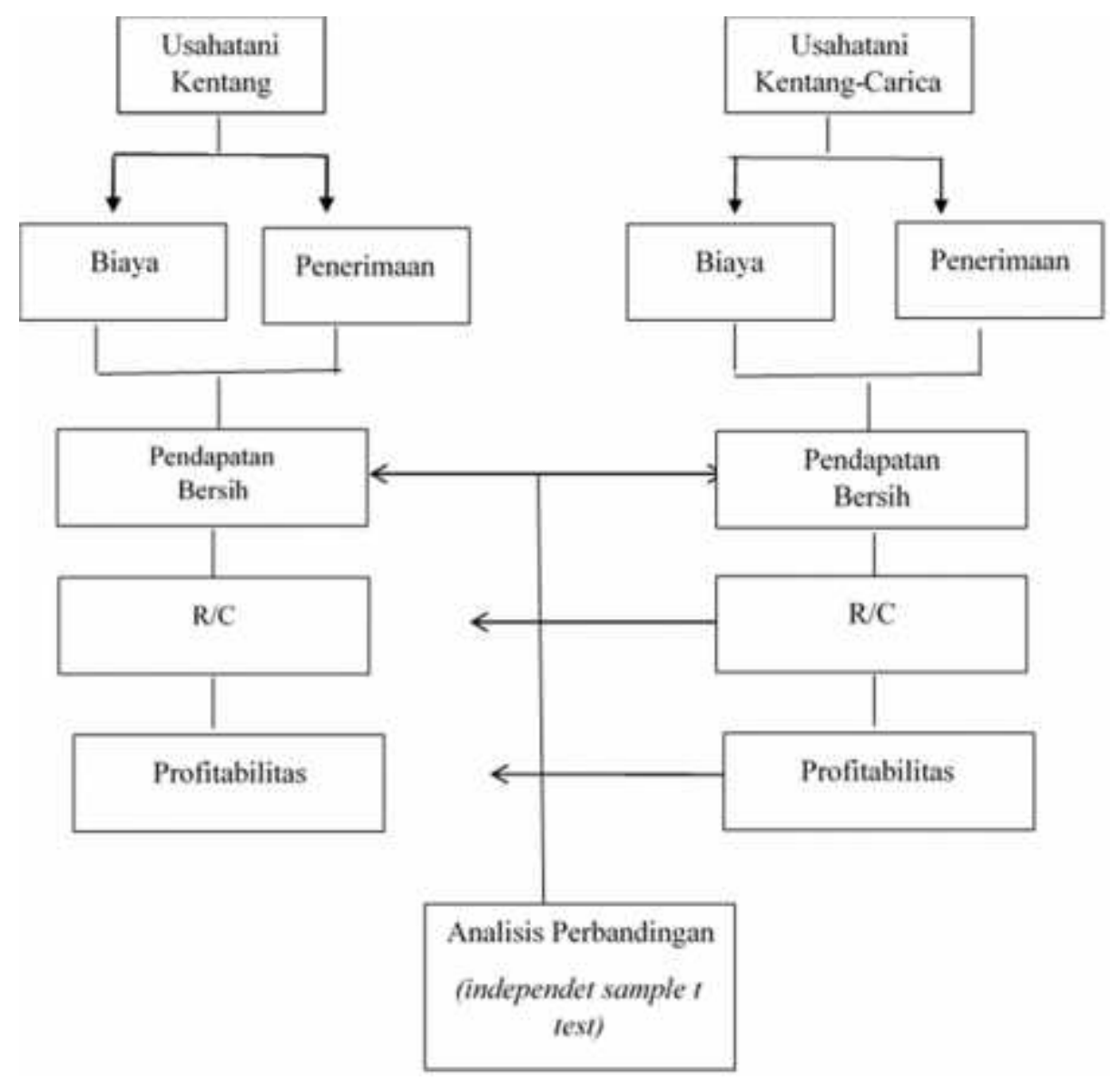

\section{Gambar 1. Kerangka Pemikiran}

\section{HASIL DAN PEMBAHASAN}

\section{Karakteristik Responden}

Berdasarkan Tabel 1 dapat diketahui dengan jumlah responden 60 yang terdiri dari 30 responden petani monokultur kentang 30 responden dan petani tumpangsari kentang-carica 30 responden. Pada pola tanam monokultur terdiri didari 25 responden berjenis kelamin laki-laki dengan persentase $83 \%$ dan 5 
responden berjenis kelamin perempuan dengan persentase 5\%. Petani menggunakan pola tanam tumpangsari carica terdiri dari 24 responden berjenis kelamin laki-laki dengan persentase 80\% dan 6 responden berjrnis kelamin perempuan dengan persentase 20\%. Petani di Desa Sembungan memiliki kisaran umur dari 21-70 tahun. Pada pola tanam monokultur kentang rata-rata umur responden 46. Sebagian besar responden berusia 51-60 tahun yang berjumlah 10 responden dengan persentase 33,33 \%. Pada pola tanam tumpangsari rata - rata umur responden yaitu 37 tahun. Sebagian besar responden berumur 41-50 tahun yang berjumlah 11 orang dengan persentase 36,66 \%. Responden petani di Desa Sembungan termasuk pada usia produktif dengan kisaran 40-60. Usia produktif pada kelompok umur 15-64, dan kelompok diatas umur 65 tahun merupakan kelompok usia tidak produktif lagi (Mantra, 2011).

Tabel 1. Data Responden Petani Kentang dan Kentang Carica di Desa Sembungan

\begin{tabular}{|c|c|c|c|c|c|}
\hline No & Aspek & $\begin{array}{l}\text { Jumlah } \\
\text { Monokultur } \\
\text { (jiwa) }\end{array}$ & $\begin{array}{l}\text { Presentase } \\
(\%)\end{array}$ & $\begin{array}{l}\text { Jumlah } \\
\text { Tumpangsari } \\
\text { (jiwa) }\end{array}$ & $\begin{array}{l}\text { Presentase } \\
(\%)\end{array}$ \\
\hline \multirow[t]{3}{*}{1} & Jenis Kelamin & & & & \\
\hline & a. Laki -Laki & 25 & 83 & 24 & 80 \\
\hline & b. Perempuan & 5 & 17 & 6 & 20 \\
\hline \multirow[t]{6}{*}{2} & Umur & & & & \\
\hline & $21-30$ & 4 & 13,33 & 9 & 30 \\
\hline & $31-40$ & 7 & 23,34 & 9 & 30 \\
\hline & $41-50$ & 8 & 26,67 & 11 & 36,67 \\
\hline & $51-60$ & 10 & 33,33 & 1 & 3.33 \\
\hline & $>61$ & 1 & 3,33 & & \\
\hline \multirow[t]{6}{*}{3} & Tingkat & & & & \\
\hline & Pendidikan & & & & \\
\hline & Tidak Sekolah & 0 & 0 & 1 & 3,33 \\
\hline & $\mathrm{SD}$ & 16 & 53,33 & 15 & 50 \\
\hline & SLTP & 8 & 26,67 & 6 & 20 \\
\hline & SLTA & 6 & 20 & 8 & 26,67 \\
\hline \multirow[t]{7}{*}{4} & Pengalaman & & & & \\
\hline & Usahatani & & & & \\
\hline & $<10$ & 1 & 3,33 & 11 & 36,67 \\
\hline & $10-20$ & 12 & 40,00 & 10 & 33,33 \\
\hline & $21-30$ & 10 & 33,34 & 6 & 20 \\
\hline & $31-40$ & 6 & 20,00 & 3 & 10 \\
\hline & $>40$ & 1 & 3,33 & & \\
\hline
\end{tabular}

Sumber: data primer diolah, (2019)

Petani kentang dengan pola tanam monokultur menempuh pendidikan hingga tingkat Sekolah Dasar, yaitu sebanyak 16 responden atau 53,33\%. Tingkat pendidikan responden responden petani kentang dengan pola tanam tumpangsari tidak jauh beda, menempuh pendidikan hingga tinggak Sekolah Dasar sebanyak 15 responden atau 50\%. Pendidikan SLTP pada petani monokultur kentang sebanyak 8 responden atau $26,67 \%$ dan pada petani tumpangsari kentang-carica sebanyak 6 
responden atau 20\%. Pendidikan SMA pada petani monokultur kentang sebanyak 6 responden atau $20 \%$ dan pada petani tumpangsari kentang-carica sebanyak 8 responden atau 26,67\%. Responden yang berpendidikan sampai stata 1 tidak ada dan tidak sekolah sebanyak 1 responden petani tumpangsari kentang carica. Tingkat pendidikan dapat menjadi faktor penentu dalam keberhasilan usahatani, karena dengan pendidikan masyarakat dapat lebih berfikir kritis dan inovatif. Tingkat pendidikan petani menentukan tingkat kompetensi yang sebagai perwujudan perilaku petani dalam melakukan perencanaan kegiatan untuk mencapai target (Dewi et al., 2014)

Pengalaman petani dengan pola tanam monokultur kentang sebagian besar 10-20 tahun, sebanyak 12 responden dengan persentase 40\%. Pengalaman petani dengan pola tanam tumpangsari kentang-carica sebagian besar kurang dari 10 tahun, sebanyak 11 responden dengan persentase 36,67\%. Rata-rata pengalaman usahatani pola tanam monokultur kentang 25 tahun, dengan pengalaman terendah 5 tahun dan tertinggi 45 tahun. Rata - rata pengalaman usahatani pola tanam tumpangsari kentang-carica 15 tahun dengan pengalaman terendah 2 tahun dan pengalaman tertinggi 45 tahun. Pengalaman usahatani adalah lamanya petani dalam melakukan usahatani dihitung berdasarkan tahun. Penngetahuan yang diperoleh pertani tidak hanya berdasarkan lamanya pengalaman usahatni, tetapi dari penyuluhan, keinginan petani untuk berkembang dan inovasi-inovasi yang kembangkan untuk menjalankan usahatani. Tidak ada pengaruh signifikan antara pengaman usahatani dengan pendapatan usahatani, artinya pengalaman yang lama pada usahatani belum tentu menjamin hasil yang diterima semakin baik (Rangkuti et al., 2014).

Tabel 2. Total Biaya Alat Luar Pola Tanam Monokultur dan Tumpangsari Berdasarkan Macam Biaya (Mei-Agustus 2018)

\begin{tabular}{|c|c|c|c|c|}
\hline \multirow[t]{2}{*}{ Macam Biaya } & \multicolumn{2}{|l|}{ Biaya Alat Luar } & \multicolumn{2}{|l|}{ Persentase } \\
\hline & Monokultur & Tumpangsari & Monokultur & Tumpangsari \\
\hline & \multicolumn{2}{|c|}{-----------Rp/ha/MT--------- } & \multicolumn{2}{|c|}{------------_\%------------ } \\
\hline Penyusutan Alat & $107.316,39$ & $186.065,44$ & 0,66 & 0,74 \\
\hline Sewa Tanah & $333.333,00$ & 0 & 2,05 & 0 \\
\hline Pajak & $49.278,00$ & $83.378,00$ & 0,30 & 0,33 \\
\hline Bibit & $6.122 .542,00$ & $11.361 .500,00$ & 37,58 & 44,95 \\
\hline Biaya Pupuk & $2.855 .646,00$ & $4.841 .849,00$ & 17,53 & 19,16 \\
\hline Biaya Pestisida & $2.778 .185,00$ & $3.543 .407,00$ & 17,05 & 14,02 \\
\hline Tenaga & $3.915 .104,00$ & $5.033 .229,00$ & 24,03 & 19,91 \\
\hline Kerja & & & & \\
\hline \multicolumn{5}{|l|}{ Keluarga } \\
\hline Bahan Bakar & $130.525,00$ & $224.675,00$ & 0,80 & 0,89 \\
\hline Jumlah & $16.291 .929,39$ & $25.274 .140,44$ & 100 & 100 \\
\hline
\end{tabular}

Sumber: data primer diolah, (2019)

Berdasarkan hasil penelitian dapat di ketahui bahwa jumlah biaya total dari usahatani monokultur kentang sebesar Rp 16.291.929,39 ha/MT dan jumlah biaya total dari usahatani tumpangsari kentang carica yaitu Rp 25.274.140,4 ha/MT. Biaya pola tanam tumpangsari lebih besar daripada pola tanam monokultur. Pada 
pola tanam tumpangsari rata - rata luas lahan responden lebih besar dari responden dengan pola tanam monokultur, sehingga biaya yang dikeluarkan seperti bibit, pupuk, pestisida, pajak dan tenaga kerja lebih besar. Luas lahan berpengaruh secara signifikan terhadap pendapatan usahatani. Semakin lahan luas maka, semakin memungkinkan menghasilkan produksi yang tinggi (Rangkuti et al., 2014). Pada biaya pola tanam tumpangsari ditambahkan juga dengan biaya pemeliharaan tanaman carica. Biaya terbesar yaitu biaya bibit dengan persentase 37,58 \% dan 44,95 . Biaya variabel terbesar dalam pembelian bibit dengan persentase $34,21 \%$ 36,39\% (Juiwati et al., 2018).

\section{Penerimaan}

Tabel 3. Penerimaan Pola Tanam Monokultur Kentang dan Ubi Kayu per Musim Tanam

\begin{tabular}{lc}
\hline \hline Komoditas & Penerimaan \\
\hline & ----------Rp/ha/MT--------- \\
Kentang & $23.829 .333,33$ \\
Ubi Kayu & $16.858 .600,00$ \\
\hline
\end{tabular}

Sumber: data primer diolah, (2019)

Penerimaan dihitung dengan mengalikan jumlah produksi (satu musim/satu tahun) dengan harga jual persatuan kg. Penerimaan juga disebut pendapatan kotor. Jumlah penerimaan akan diperoleh dari suatu proses produksi dengan mengalikan jumlah hasil produksi dengan harga produk yang berlaku pada saat itu (Daroini dan Nafingi, 2014). Berdasarkan hasil penelitian dapat diketahui bahwa penerimaan usahatani monokultur kentang sebesar Rp 23.829.333,33 ha/MT dan usahatani monokultur ubi kayu sebesar Rp. 16.585.600 ha/MT (Muizah et al., 2013). Usahatani kentang menghasilkan penerimaan lebih besar dibandingkan dengan usahatani ubikayu. Harga jual kentang yaitu Rp. 8.000/kg dan untuk ubi kayu dijual dengan harga 900/kg. Permintaan kentang di Indonesia cukup tinggi karena kentang dapat dijadikan beberapa bahan olahan makanan seperti kripik kentang, snack berbahan dasar kentang dan makanan berbahan dasar kentang cukup populer. Hal ini mengakibatan harga jual kentang lebih besar dari ubi kayu (Kiloes et al, 2016)

Tabel 3. Penerimaan Pola Tanam Tumpangsari Kentang-Carica dan Kopi-Kubis

\begin{tabular}{lc}
\hline \hline Komoditas & Penerimaan \\
\hline & -------------Rp/ha/MT------------- \\
Kentang-Carica & $43.188 .355,33$ \\
Kubis-Kopi & $30.321 .481,66$ \\
\hline
\end{tabular}

Sumber: data primer diolah, (2019)

Penerimaan pola tanam tumpangsari kentang-carica lebih besar dibandingkan pola tanam tumpangsari kopi-kubis. Penerimaan pada usahatani dengan polatanam tumpangsari kopi-kubis sebesar Rp 30.321.481,66 (Pelawi et al., 2016). Harga jual kentang lebih besar dibandingkan dengan harga jual kubis, akan tetapi harga jual carica lebih kecil dibandingkan harga jual kopi. Kopi dan carica merupakan tanaman tahunan yang memiliki nilai investasi pohon. Pola tanam kubis-kopi memiliki produktivitas cukup redah sehingga memiliki penerimaan lebih kecil dibandingkan dengan kentang-carica. 


\section{Pendapatan Bersih}

Pendapatan bersih dihitung dengan mengurangkan penerimaan (pendapatan kotor yang diperoleh dari hasil kali jumlah prodoksi dengan harga satuan yang ditetapkan) dengan biaya yang telah dikeluarkan dalam kegiatan usahtani. Berdasarkan hasil penelitian dapat diketahui bahwa pendapatan bersih usahatani monokultur kentang sebesar Rp 7.537.404,33 ha/MT dan usahatani monokultur ubi kayu sebesar Rp. 9.031.498,00 ha/MT(Muizah et al., 2013). Biaya yang digunakan dalam usahatani kentang lebih besar karena dalam budidaya kentang harus intensif. Biaya merupakan salah satu faktor yang berpengaruh terhadap pendapatan bersih suatu usahatani. Pendapatan pertanian dinyatakan dalam bentuk uang setelah hasil kotor produksi (penerimaan) dikurangi dengan biaya produksi sehingga diperoleh pendapatan bersih petani (Wanda, 2015).

Tabel 4. Pendapatan Bersih Pola Tanam Monokultur Kentang dan Ubi Kayu per Musim Tanam

\begin{tabular}{lc}
\hline \hline Komoditas & Pendapatan Bersih \\
\hline Kentang & $7.537 .404,33$ \\
Ubi Kayu & $9.031 .498,00$ \\
\hline
\end{tabular}

Sumber: data primer diolah, (2019)

Pendapatan bersih pola tanam tumpangsari kentang-carica lebih besar dibandingkan pola tanam tumpangsari kopi-kubis. Pendapatan bersih pada usahatani dengan polatanam tumpangsari kopi-kubis sebesar Rp 15.721.785,33 (Pelawi et al., 2016). Hal ini dikarenakan penerimaan pada usahatani kentang-carica lebih besar dibandingakan dengan usahatani kubis dan kopi. Pada usahatani dengan pola tanam tumpangsari menghasilkan pendapatan bersih yang besar. Pola tanam mempengaruhi produktivitas dari suatu usahatani, peningkatan produksi dapat melalui tanam ganda yaitu tumpangsari. Pola tanam tumpangsari dapat keimbangan untur hara dalam tanaman sehingga dapat mengoptimalkan proses budidaya pada tanaman. Pola tanam tumpangsari memberikan produktivitas lebih besar dan dapat menekan biaya seperti biaya tenaga kerja, sehingga dapat meningkatkan pendapatan bersih. Keuntungan pada pola tanam tumpangsari yaitu mengurangi risiko kerugian yang disebabkan fluktuasi harga pertanian, dapat menekan biaya operasional seperti tenaga kerja dan biaya pemeliharaan tanaman dan dapat meningkatkan produktifitas tanah sekaligus memperbaiki sifat tanah (Darwis, 2017).

Tabel 5. Pendapatan Bersih Pola Tanam Tumpangsari Kentang-Carica dan KopiKubis per Musim Tanam

\begin{tabular}{lc}
\hline \hline Komoditas & Pedapatan Bersih \\
\hline & --------- Rp/ha/MT------- \\
Kentang-Carica & $17.914 .251,00$ \\
Kubis-Kopi & $15.721 .785,33$ \\
\hline
\end{tabular}

Sumber: data primer diolah, (2019)

\section{Profitabilitas}

Profitabilitas digunakan untuk mengukur penggunaan biaya dapat memperoleh berapa \% pendapatan bersih. Menghitung profitabilitas menggunakan 
jumlah pendapatan bersih dibagi dengan biaya yang dikeluarkan. Berdasarkan hasil penelitian dapat diketahui bahwa besar profitabilitas usahatani dengan pola tanam monokultur sebesar 44,07\%. Usahatani dengan pola tanam tumpangsari memiliki profitabilitas sebesar 60,39\%. Semakin tinggi nilai profitabilitas maka, keuntungan yang didapatkan semakin besar. Nilai rasio profitabilitas semakin baik maka semakin baik pula keuntungan yang diperoleh dari suatu usahatani. (Ariyani et al., 2017). Nilai profitabilitas lebih tinggi dari suku bunga Bank BRI per musim yaitu $1,92 \%$ dengan signifikasi 0,000 maka usaha tani monokultur kentang dan tumpangsari kentang-carica layak karena mampu menghasilkan keuntungan. Nilai profitabilitas lebih dari suku bunga Bank yang telah ditentukan maka usaha tersebut menguntungkan (Budiraharjo et al., 2011)

\section{R/C Ratio}

$\mathrm{R} / \mathrm{C}$ ratio digunakan untuk mengukur usaha layak dilanjutkan (menguntungkan) atau tidak. $\mathrm{R} / \mathrm{C}$ ratio dihitung dengan total penerimaan dibagi dengan total biaya yang dikeluarkan dalam usaha tani. $\mathrm{R} / \mathrm{C}$ ratio merupakan analisis yang digunakan untuk mengetahui efisiensi dan efektivitas penggunaan modal (Warisno dan Dahana, 2018). Analisis ini membandingkan biaya yang digunakan dan penerimaan yang diperoleh. Berdasarkan hasil penelitian rata-rata nilai dari $\mathrm{R} / \mathrm{C}$ ratio untuk pola tanam monokultur kentang sebesar 1,04, berarti usahatani tersebut menguntungkan karena memiliki $\mathrm{R} / \mathrm{C}$ ratio lebih dari 1 . Setiap Rp 1,- modal yang dikeluarkan menghasilkan penerimaan sebesar Rp 1,04,- . Nilai $\mathrm{R} / \mathrm{C}$ ratio pada usahatani pola tanam tumpangsari kentang carica 1,60 . Usahatani menguntungkan karena memiliki nilai $\mathrm{R} / \mathrm{C}$ ratio lebih dari 1 . Setiap $\mathrm{Rp} 1$,- modal yang dikeluarkan menghasilkan penerimaan sebesar $\mathrm{Rp} 1,60,-$. R/C ratio ini menunjukan produktivitas modal, dimana setiap 1 rupiah modal yang dikeluarkan akan akan menghasilkan penerimaan sebesar dari hasil $\mathrm{R} / \mathrm{C}$ ratio (Warisno dan Dahana, 2010).

\section{Analisis Pendapatan Bersih, Profitabilitas, R/C Ratio Usahatani Monokultur Kentang dan Tumpangsari Kentang Carica}

Nilai $\mathrm{P}(\mathrm{T} \leq \mathrm{t})$ one-tail dari uji $t$ independent untuk pendapatan bersih usahatani adalah 0,007. Nilai $\mathrm{P}(\mathrm{T} \leq \mathrm{t})$ one-tail $<0,05$ sehingga dapat diartikan pendapatan bersih usahatani dengan pola tanam tumpangsari kentang carica lebih besar dari usahatani dengan pola tanam monokultur kentang. HO ditolak, Hl diterima. Penggunaan lahan tumpangsari lebih intensif dan lebih mengoptimalkan penggunaan lahan. Pola tanam tumpangsari terdapat diversivikasi tanaman sehingga lebih banyak total produksi (Muhsin, 2011).

Nilai signifikasi dari uji $t$ independent untuk profitabilitas usahatani adalah 0,007. Nilai $\mathrm{P}(\mathrm{T} \leq)$ one-tail < 0,05 sehingga dapat diartikan profitabilitas usahatani dengan pola tanam tumpangsari kentang carica lebih besar dengan usahatani dengan pola tanam monokultur kentang. HO ditolak, Hl diterima. Kemampuan untuk mendapatkan laba lebih menguntungkan dan efisien menggunakan pola tanam tumpangsari. Profitabilitas yang baik apabila biaya yang dikeluarkan semakin kecil dan keuntungan yang diperoleh semakin besar. Profitabilitas tinggi dapat dikatakan sebagai usahatani yang efektif dan efisien dalam penggunaan faktor produksi. Analisis profitabilitas akan mengukur menggunakan rasio profitabilitas 
akan mengukur efektivitas manajemen secara keseluruhan yang ditujukan pada besar kecilnya tingkat keuntungan yang diperoleh. Semakin tinggi rasio profitabilitas maka keuntungan yang dihasilkan semakin baik(Ariyani et al., 2017).

Nilai signifikasi dari uji tindependent $\mathrm{R} / \mathrm{C}$ ratio adalah 0,007 . Nilai $\mathrm{P}(\mathrm{T} \leq \mathrm{t})$ onetail 0,007 $\leq$ 0,05 sehingga dapat diartikan $\mathrm{R} / \mathrm{C}$ ratio usahatani dengan pola tanam tumpangsari kentang - carica lebih besar dari pola tanam monokultur kentang Pada pola tanam tumpangsari memiliki jumlah produksi lebih tinggi karena terdapat dua komoditi yang diperhitungkan yaitu tanaman kentang dan tanaman carica. Standart wilayah untuk produksi komoditas kentang di Kabupaten Wonosobo 16.177 /ha (Badan Pusat Statistika, 2018). Pola tanam tumpangsari maupun monokultur belum ada yang memenuhi standar produksi komoditas kentang di Wonosobo.

\section{KESIMPULAN DAN SARAN}

\section{Kesimpulan}

Berdasarkan hasil penelitian mengenai analisis pendapatan usahatani monokultur kentang dan kentang-carica dapat disimpulkan sebagai berikut: Pendapatan bersih dari usahatani dengan pola tanam tumpangsari kentang carica lebih besar secara nyata dari usahatani dengan pola tanam monokultur kentang. Pendapatan bersih usahatani tumpangsari kentang-carica yaitu $\mathrm{Rp}$ 17.386.588,2/ha/MT dan monokultur kentang yaitu Rp 7.537.404,33 ha/MT. Profitabilitas dari usahatani dengan pola tanam tumpangsari kentang carica lebih besar secara nyata dari usahatani dengan pola tanam monokultur kentang. Profitabilitas usaha tani monokultur kentang yaitu $44,07 \%$ dan pola tanam tumpangsari kentang-carica yaitu 60,39\%. R/C ratio dari usahatani dengan pola tanamtumpangsari kentang carica lebih besar secara nyata dari usahatani dengan pola tanam monokultur kentang. $\mathrm{R} / \mathrm{C}$ ratio usaha tani dengan pola tanam tumpangsari yaitu 1,60 dan usaha tani dengan pola tanam monokultur kentang yaitu 1,44

\section{Saran}

Berdasarkan hasil penelitian, maka saran yang penulis berikan adalah pola tanam yang dapat di terapkan di Desa Sembungan Kabupaten Wonosobo menggunakan pola tanam tumpangsari. Pola tanam tumpangsari dapat memberikan pendapatan bersih,profitabilitas dan $\mathrm{R} / \mathrm{C}$ ratio yang lebih besar dibandingkan dengan pola tanam monokuktur.

\section{DAFTAR PUSTAKA}

Ariyani, D. M. A., Santoso, S. I. dan Setiadi, A. (2017) 'Analisis Profitabilitas Usaha tani Jambu Biji Getas Merah Di Kabupaten Kendal', 35(2), pp. 10-18.

Badan Pusat Statistika (2015) Wonosobo Dalam Angka 2014, Badan pusat Statistika. Wonosobo.

Badan Pusat Statistika (2018) Kejajar Dalam Angka 2017, Badan Pusat Statistika. Wonosobo.

Budiraharjo, K., Handayani, M. dan Sanyoto, G. (2011) 'Analisis Profitabilitas Usaha Penggemukan Sapi Potong Di Kecamatan Gunungpati Kota Semarang', Mediagro, 7(1), pp. 1-9. 
Daroini, A. dan Nafingi, A. K. (2014) 'Analisis Biaya dan Pendapatan Usaha Peternakan Sapi Potong di UD. Haiva Jaya Tulungagung', Cendekia, 12(2), pp. 98-104.

Darwis, K. (2017) Ilmu Usahatani: Teori dan Penerapan. Makasar: CV Inti Mediatama. Available at:

https:// books.google.co.id/books?id=FRJJDwAAQBAJ\&pg=PR3\&dq=Ilmu+U sahatani+Teori+dan+Penerapannya.\&hl=en\&sa=X\&ved=0ahUKEwiGqsD56o PiAhXc63MBHYOZCFcQ6AEIKjAA\#v=onepage\&q=Ilmu Usahatani Teori dan Penerapannya.\&f=false (Accessed: 5 May 2019).

Dewi, I. N. et al. (2014) 'Karakteristik Petani dan Kontribusi Hutan Kemasyarakatan (HKm) Terhadap Pendapatan Petani di Kulon Progo', Ilmu Kehutanan, 12(1), pp. 86-98.

Ekowati, T. et al. (2014) Buku Ajar Usahatani. Semarang: UPTD UNDIP Press Semarang.

Juiwati, T. A., Prayuginingsih, H. dan Prawitasari, S. (2018) 'Analisis Komparatif Usahatani Kentang Atlantik dan Kentang Granola di Kecamatan Sempol', Agriibest, 02(02), pp. 131-146.

Khasanah, N. (2016) 'Analisis Komparatif Monokultur Ubikayu Dengan Tumpangsari Ubikayu-Kacang Tanah Di Banyumas, Agros, 18(2), pp. 149-157.

Kiloes, A. M., Sayekti, A. L. dan Anwarudin Syah, M. J. (2016) 'Evaluasi Daya Saing Komoditas Kentang di Sentra Produksi Pangalengan Kabupaten Bandung', Jurnal Hortikultura, 25(1), p. 88.

Mantra, I. B. (2011) Demografi umum. Yogyakarta: Pustaka Pelajar.

Muhsin (2011) 'Studi Komparative Usahatani Kapas Pola Tumpangsari dengan Pola Monokultur', Genec Swara, 5(2), pp. 109-115.

Muizah, R., Supardi, S. dan Shofia, N. A. (2013) 'Analisis Pendapatan Usahatani Ubi Kayu (Manihot esculenta crantz) Studi Kasus Desa Mojo Kecamatan Cluwak Kabupaten Pati', Mediagro, 9(2), pp. 55-67.

Pelawi, Y. G., Ginting, R. dan Chalil, D. (2016) 'Analisis Komparasi Usahatani antara Pola Tanam Tumpangsari Tanaman Kopi dan Kubis dengan Kopi Monokultur dan Kubis Monokultur', Soca, 5(5), pp. 1-15.

Pramono, A. A. et al. (2010) Pengelolaan Hutan Jati Rakyat: Panduan Lapangan untuk Petani. Bogor: Center fo International Forestry Research.

Rahayu, E. S. dan Pribadi, P. (2012) 'Levels of Vitamin and Mineral in Fresh Flesh and Wet Weetened Karika Dieng (Carica pubescens lenne \& k. koch)', Biosaintifika, 4(2), pp. 89-97.

Rangkuti, K. et al. (2014) 'Pengaruh Faktor Sosial Ekonomi Terhadap Pendapatan Petani Jagung', Agrium, 19(1), pp. 561-565.

Sugiyono (2012) 'Metode Penelitian Kuantitatif, Kualitatif dan R \& D', in Alfabeta. Bandung.

Suryani and Hendryadi (2015) Metode Riset Kuantitatif: Teori dan Aplikasi pada Penelitian Bidang Manajemen dan Ekonomi Islam. Jakarta: Prenadamedia Group.

Wahyuni, A., Alamsyah, Z. and Damayanti, Y. (2018) 'Analisis Komparasi 
Pendapatan Usahatani Kelapa dalam Pola Monokultur dan Tumpangsari di Kecamatan Mendahara Kabupaten Tanjung Jabung Timur', Ilmiah SosioEkonomika Bisnis, 21(1), pp. 1-13.

Wanda, F. A. (2015) 'Analisis Pendapatan Usaha Tani Jeruk Siam ( Studi Kasus Di Desa Padang Pangrapat Kecamatan Tanah Grogot Kabupaten Paser', Jornal Ilmu Administrsi Bisnis, 3(3), pp. 600-611.

Warisno. and Dahana, K. (2018) Peluang usaha dan budi daya cabai - PT Gramedia Pustaka. Jakarta.

Warisno and Dahana, K. (2010) Meraup Untung Dari Olahan Kedelai - Agromedia Pustaka. Jakarta. 